\title{
Implication of Engineering Project Management in Small and Medium Enterprise: Malaysian Perspective
}

\author{
Yahya A. Alazemi and Erry Y. T. Adesta

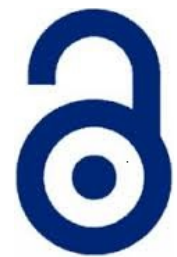 \\ Received: 31 August 2018 \\ Accepted: 13 September 2018 \\ Published: 01 December 2018 \\ Publisher: Deer Hill Publications \\ (C) 2018 The Author(s) \\ Creative Commons: CC BY 4.0
}

\begin{abstract}
Integrated project management includes the collection, combination and coordination of project elements in becoming a set of project management. In this research, three important aspects of project management such as life cycles, success factors and areas of problem and solutions in small to medium enterprises (SMEs) are presented. A survey is conducted in Malaysia in order to measure the degree of awareness and implementation of project management in SMEs. The collected data was analysed using statistical methods named Statistical Package for the Social Science (SPSS). The analysis showed that $80 \%$ of respondents with mean 1.20 and standard deviation 0.447 agree that project management is most important for company performance. Only $66.7 \%$ respondents really understand the basics of project management. In terms of project goals, the most respondents stated that their project always met performance goals with 4.20 mean and 0.837 standard deviation. According to $80 \%$ of the respondents, planning and control are the main criteria to the success of projects and organization with 4.80 mean and 0.447 standard deviation.
\end{abstract}

Keywords: Project management, Life cycle, Small and medium enterprise, SME, Success factor

\section{INTRODUCTION}

Nowadays, it is widely acknowledged that small and medium scale enterprises (SMEs) are the most important key in overall national development. They play an important role in the economy, both in terms of employment and economic development and growth. As a fact, according to SME Annual Report 2015/2016, SMEs consistently contributed to the increasing of percentage of gross domestic product (CDP), employment and export. SMEs contributed $36.3 \%$ to GDP in 2015 from only below $30 \%$ in 2005 while the employment share increase $8.7 \%$ from $56.8 \%$ in 2005 to $65.5 \%$ in 2015 . In addition, exports also show better growth from $16.4 \%$ in 2010 to $17.6 \%$ in $2015[1,2]$.

Back in 1996, Small \& Medium Industries Development Corporation (SMIDEC) is a responsible agency to develop SMEs to be competitive in the global market. The year 2004 marks another chapter in SMEs history with the establishment of the National SME Development Council (NSDC) that responsible in formulating strategies, coordinating programs, encourage partnership and also to ensure the effective implementation in the development of SMEs across all economic factors. Four years after NSDC was established, SMIDEC took over again NSDC role in SMEs development. A year after, on 2 October 2009, SMIDEC was officially rebranded to Small to Medium Enterprise Corporation Malaysia (SME Corporation Malaysia) which now is the national organization central point regarding information and activities for the development of progressive SMEs through various platforms and programs.

On the other hand, SMEs have various definitions with time, experience, country, context and global articulation of the SMEs catalytic role. According to Economic Census (2011), SMEs in Malaysia are defined for only two sectors. The first one is manufacturing sector with a sales turnover of less than RM 25 million or less than 150 full time employees. The second one is service sectors which have a sales turnover of less than RM 5 million or less than 50 fulltime employee [3].

Y. A. Alazemi ${ }^{1} \otimes$ and E. Y. T. Adesta ${ }^{2}$

Department of Manufacturing and Materials Engineering

International Islamic University Malaysia

PO Box 10, 50728 Kuala Lumpur, Malaysia

'E-mail: eng-yahya2000@hotmail.com

2E-mail: eadesta@iium.edu.my

Reference: Alazemi, Y. A. and Adesta, E. Y. T. (2018). Implication of Engineering Project Management in Small and Medium Enterprise: Malaysian Perspective. International Journal of Engineering Materials and Manufacture, 3(4), 208-215. 
According to SME Corporation Malaysia in SMEs annual report 2015/2016, under manufacturing sector, they must have sales turnover not exceeding RM50 million or full-time employees not exceeding 200. Apart from that, in services sales turnover not exceeding RM20 million or full-time employees not exceeding 75 . To be specific about the definition, there are facts that all SMEs must be entities registered with SSM or other equivalent bodies. It however, excludes companies that are multinational corporations (MNCs), government-linked companies (CLCs) and state-owned enterprises [2].

SMEs need to build up their competitiveness and quality to match or exceed the competition where project management is the key for success and growth. Project management was developed initially in the heavy engineering industries, particularly construction, defence, aerospace and shipbuilding [4]. It later evolved to address smaller projects and medium-sized projects in large firms [5] to establish discipline that helps in defining, plan and implement successful projects. The failure SMEs that practice project management is less in economic system. Small firms have several disadvantages in innovation such as limited cash flow, knowledge and skills, and a low sales volume (Rogers, 2004). In order to achieve economic development and growth, SMEs should spend 3 percent of their turnover on innovation. As such, the objectives of this research are as follows.

1. To measure the degree of awareness and implementation of project management in SMEs.

2. To identify problem areas in SMEs to apply integrated engineering project management.

3. To recommend solutions and way forward to apply integrated engineering project management for growth and sustainability of SMEs.

The scope of this project is focusing on manufacturing sector of SMEs in Malaysia and their practices with integrated engineering project management. A survey will be conducted using data collection questionnaire. Then data will be analysed to make recommendations for applying integrated engineering project management. The significance of this study is that it will create awareness for the implementation of project management in SMEs manufacturing sectors.

\section{LITERATURE REVIEW}

To define SMEs, according to the World Bank, three quantitative criteria is used which is total assets in U.S. dollars, number of employees and annual sales in U.S. dollars. To be considered as micro, small or medium business, the enterprises must meet the requirement of those three criteria or at least one financial criteria. Number of employees is the most common criteria that always use to define between medium, small and micro enterprise which is the largest number of sources to define SMEs in 2003, stated that SMEs must have a cut-off range of 0-250 employees. The European Union has the most influence among all SMEs definitions. However, that definition is only limited for institutions and businesses seeking funding for it. According to the World Bank statistics, out of 132 countries include in the research, 46 of them or a third define SMEs is an enterprise with less than 250 employees. However, each country has their own way to define SMEs specifically according to their own economy. Table 1 shows the number of employees in different countries to classify the size of the company. Concentrating on manufacturing, there is numerous number of sub-sectors as shown in Table 2. From the statistics shown in Table 2, the highest percent of the sector in SMEs is $24 \%$, which is wearing apparel sector, drop to 15.14 per cent for food and beverages and 10.45 percent in metals products. These are top three sectors, which are more than 10 percent and have a high number of percent for a percentage of SMEs. On the other hand, the least concentration of SMEs that stay for two from the bottom were coke and refined petroleum products ( 0.17 per cent) and the last one is tobacco products ( 0.16 per cent). The regional orientation of manufacturing sector SMEs are listed in Table 3 . It shows that Selangor has the highest number of SMEs with 8,314 establishments (22\%). This was followed by Johor with 4,828 establishments (12.8\%) [1, 2].

Table 1: Size of Firms by Number of Employees in different countries

\begin{tabular}{lccccc}
\hline & Micro & Small & Medium & SME & Large \\
\hline EU & $1-9$ & $10-49$ & $50-249$ & $1-249$ & $250+$ \\
Australia & $0-9$ & $10-49$ & $50-199$ & $0-199$ & $200+$ \\
Canada & $0-9$ & $10-49$ & $50-499$ & $0-499$ & $500+$ \\
Japan & $4-9$ & $10-49$ & $50-249$ & $1-249$ & $250+$ \\
Korea & $5-9$ & $10-49$ & $50-199$ & $5-199$ & $200+$ \\
Mexico & $0-10$ & $11-50$ & $51-250$ & $1-250$ & $250+$ \\
New Zealand & $1-9$ & $20-49$ & $50-99$ & $0-99$ & $100+$ \\
Turkey & $1-19$ & $20-49$ & $50-249$ & $1-249$ & $250+$ \\
USA & $1-9$ & $10-99$ & $100-499$ & $1-499$ & $500+$ \\
Malaysia & $1-4$ & $5-74$ & $75-200$ & $5-200$ & $200+$ \\
\hline
\end{tabular}


Table 2: Number of SMEs in Manufacturing Sectors (Economic Census, 2011).

\begin{tabular}{lcc}
\hline \multicolumn{1}{c}{ Sub-sector (Manufacture) } & Number of SMEs & \% SMEs \\
\hline Wearing apparel & 9,088 & 24.00 \\
Food products & 5,731 & 15.14 \\
Fabricated metal products & 3,958 & 10.45 \\
Printing and reproduction of recorded media & 2,918 & 7.71 \\
Furniture & 1,843 & 4.87 \\
Rubber and plastics products & 1,756 & 4.64 \\
Wood and products of wood and cork & 1441 & 3.81 \\
Other non-metallic mineral products & 1,373 & 3.63 \\
Machinery and equipment & 1,203 & 3.18 \\
Basic metals & 1,083 & 2.86 \\
Chemicals and chemical products & 961 & 2.54 \\
Textiles & 959 & 2.53 \\
Repair and installation of machinery and equipment & 913 & 2.41 \\
Paper and paper products & 828 & 2.19 \\
Electrical equipment & 622 & 1.64 \\
Computer, electronic and optical products & 446 & 1.18 \\
Motor vehicles, trailers and semi-trailers & 431 & 1.14 \\
Leather and related products & 376 & 0.99 \\
Other transport equipment & 328 & 0.87 \\
Beverages & 285 & 0.75 \\
Basic pharmaceutical products and pharmaceutical preparations & 192 & 0.51 \\
Coke and refined petroleum products & 63 & 0.17 \\
Tobacco products & 60 & 0.16 \\
\hline
\end{tabular}

Table 3: SMEs in the manufacturing sector by state (Economic Census, 2011)

\begin{tabular}{lcc}
\hline State in Malaysia & Number of SME & \% of SME \\
\hline Pahang & 1,305 & 3.4 \\
Sabah & 1,382 & 3.7 \\
Negeri Sembilan & 1,495 & 3.9 \\
Others & 1,507 & 4.0 \\
Terengganu & 1,782 & 4.7 \\
Kelantan & 1,814 & 4.8 \\
Sarawak & 1,977 & 5.2 \\
Pulau Pinang & 2,614 & 6.9 \\
Kedah & 2,809 & 7.4 \\
Perak & 3,833 & 10.1 \\
W. P. Kuala Lumpur & 4,201 & 11.1 \\
Johor & 4,828 & 12.8 \\
Selangor & 8,314 & 22.0 \\
\hline
\end{tabular}

\subsection{Project Management and Life Cycle}

Classical management is usually considered to have five functions or principles which includes planning, organizing, staffing, controlling and directing. These days, project management can be defined in the view of short-term goals including planning, organizing, directing, and monitoring of company resources. In addition, it comes with a goal to complete particular goals and objectives that has been made earlier. The Project Management Life Cycle has four phases which is initiation, planning, execution and closure. Macro and micro viewpoints are two different types of approach to determine the success of project management. In the macro viewpoint completion and satisfaction are the two criteria to measure project success. On the other hand, the completion criteria alone are sufficient for the micro viewpoint of project success. Team members and project leader must discuss at the early stage of the project, which is initiation phase about the criteria in measuring project success. This will help them to prevent from heading in the wrong directions that will result in a failure of a project due to different objectives and goals toward a particular project [6]. Many authors attempted to add more dimension to the basic elements of project success. Example includes customer satisfaction that is one of the most significant elements nowadays to measure performance along with the concept of Total Quality Management (TQM) [7, 8]. 


\subsection{The Way Forward}

These ways forward proposing some solutions in dealing with problem areas associated with project management for successful economic growth in SMEs.

1. It has to be clear from the beginning that there will be regularly scheduled updates for the duration and tasks of the project. Let everyone in the team know that status updates and progress are expected from them and they have to communicate clearly in any issues or delays in particular projects.

2. The project manager should start by calling the team together and delivering a presentation about the project management before execute and its significance towards everybody tasks. Managers have to generate a sense of urgency about the project and how the project management will helps them to achieve objectives, leading the team to always think that they must always improve their knowledge in project management to complete their tasks in particular projects.

3. The project manager also responsible for figuring out who will be assigned to each task and for ensuring there's a fair allocation of talent and skills in each team member across projects.

4. An SME should have comprehensive reports and documentations on problem areas before project management implementations. This database could be used for planning and decision-making towards total elimination of all problems, especially regarding the project [ 9 .

5. For the government, there should be a law prohibiting noncertified project managers from handling projects to reduce failure in implementation of project management. With the best and certified project manager, rate of success will increase rapidly [9]. As a result, the problem of lack of knowledge and lack of experienced project manager will be decreased.

6. A successful project manager should always have weekly status meetings with team members, to check if everything was achieved as per the timeline, what issues happens that could disturb the project timeline.

7. To have more expertise in project management, higher educational levels should think to include project management as a compulsory subject especially in engineering program. They can consider putting this project management as a top program such as degree level [9].

\section{RESEARCH METHODOLOCY}

In the early initiative to boost the research knowledge, the author pursued literature search from related book, journal, research paper, dissertation, article, internet based reading material and anything related to any terms that was addressed. This is necessary for the author and the readers to understand what is project management and SMEs and the connection between project management and SMEs.

The reviewed literature always regarding on project management, SMEs, and their connection. The history of project management as a starter, followed by definition and profile of SMEs. This paper also concludes project life cycle methodology, success factor and problem areas focusing on small to medium manufacturing (SMEs) area. At the end of the literature review, this paper gives the solution and ideas on how to solve the problem when applying project management in SMEs through a reading in journals and websites. To occupy in this research gap, the dissertation will combine all the facts, theories and others research paper gathered regarding project management and SMEs. To achieve the last objective, which is to measure the awareness and implementation of project management in small and medium enterprises (SMEs), survey will be conducted. The survey focuses on manufacturing related SMEs in the state of Pahang and Sarawak of Malaysia.

The company is chosen for SME Corporation website. SME Corporation Malaysia is a central coordinating agency under the Ministry of International Trade and Industry Malaysia that formulates overall policies and strategies for SMEs and coordinates the implementation of SMEs development programs across all related ministries and agencies. Subsequently, the company also must be in manufacturing related services. In this study, the company is chosen in Pahang and Sarawak only considering the largest state in peninsular East Malaysia. Data from respondent is gained through a questionnaire that was distributed to the engineer of the SMEs manufacturing companies.

\subsection{Questionnaire Design}

A set of questionnaires have been designed in such a way to increase respondent's interest regarding the topic, and easy to understand. The questionnaire is attractive, simple yet comprehensive and it is based on the objectives of the study. The beginning part in questionnaire aimed to identify the basic background of respondents, their position and experience in their company and to determine an organization of the company in general. In the first part, number of employees will be a key question in order to make sure that the respondents are in small and medium enterprises (SMEs). There are two sections in this questionnaire. Section A is about project management in general. It is to measure the understanding of the respondents on project management concept. The respondents may hear and apply project management in their organization. Section B is about the implementation of project management and whether respondents will be familiar with the project management tools or not. Basically, section $A$ and $B$ are related to each other to make sure the reliability of the questions and also the results. 


\subsection{Sample Size}

One of the concerns in survey is the number of samples is needed. A larger sample can contribute to accurate results, but excessively big data is difficult to handle. There are many things that can affect how well our sample reflects the population and therefore how valid and reliable our conclusions will be [10]. The man characteristics of the company is the small and medium enterprises. To ensure that the company is SMEs, the company is chosen for SME Corporation website. SME Corporation Malaysia is a central coordinating agency under the Ministry of International Trade and Industry Malaysia that formulates overall policies and strategies for SMEs and coordinates the implementation of SMEs development programs across all related ministries and agencies. Subsequently, the company also must be in manufacturing related services. In this study, the company is chosen in Pahang and Sarawak only considering the largest state in peninsular East Malaysia. Data from respondent is gained through a questionnaire that was distributed to the engineer of the SMEs manufacturing companies.

i. Population Size: In this report, the research only focuses on small to medium sized companies in the manufacturing sector. As a result, the population size for this research has been determined to be 50 .

ii. Confidence Interval: This confidence interval determines how close the answer of our sample to the true value in the population. The smaller confidence interval, the closer to the true value. In this survey, the confidence interval will be $5 \%$.

iii. Confidence Level: It defines the method to determine whether the sample accurately reflects the population. $95 \%$ confidence will be chosen and it will contribute to $Z$ Score $=1.96$

iv. Standard of Deviation: The value of variance expected in the response. The safest decision is to use 0.5. This is the most forgiving number and ensures that your sample will be large enough.

\subsection{Questionnaires Distribution}

The set of questionnaires was distributed among the targeted respondent. Type of respondent, which will be focusing on engineer position which was determined earlier so that it can meet the objectives with enough data to be collected. At first, the companies were selected on Manufacturing SME. The details of engineer in SME and Manufacturing companies were collected by a call to the company in the SME and as well as manufacturing. Using Google Form that distributed through email.

\subsection{Survey Analysis}

Collected data were analysed using SPSS to ensure the reliability of the data. The data from the findings will be converted to mathematical data. It is more appropriate to have the data in mathematical form to allow greater understanding and efficiency. On the other hand, analysis can be done easily with mathematical data. The result from the software will stay as it is with the facts and figure provided by the software without any editing on its data to preserve the engineering ethics.

\section{RESULTS AND DISCUSSIONS}

A total number of 45 survey questionnaire has been distributed through email on November 2016 to study and measure the awareness and implementation of integrated project management in small to medium manufacturing companies (SMEs). To increase the number of possible respondents out of total distributed, the email was sent two times in one month by include form in an email and also by attaching the link in the email only. However, only five feedbacks received through giving the percentage $11.11 \%$ of the total survey distributed. The involved companies are:

\subsection{Reliability Test}

In this study, reliability test is done in all area of study using Statistical Package for the Social Sciences (SPSS) software and value of Cronbach's Alpha. IBM SPSS Statistics version 23 was used in this study. From this software, value of cronbach's alpha is extracted to be use in analyzing the reliability of the data. In facts, Cronbach's Alpha is a measure of internal consistency, that is, how closely related a set of items are as a group. It is considered a measure of scale reliability.

This section discussed the reliability test on Introduction to Project Management (Section A). The number of items in section $A$ is based on four statements of project management. All the 4 items in this section produce both 0.800 on Cronbach's Alpha and Cronbach's Alpha Based on Standardized Items respectively. This section A also gives a mean value of 6, 0.5 for a variance and 0.707 for the standard deviation. In section $B$, number of items is based on all questions in that section. From the total time taken to finish a project, followed by project management tools. The remaining two are scale questions, which are on goals and objectives of a project according to a plan and also the important of success criteria in projects and organization (Table 5). For both Cronbach Alpha and Cronbach Alpha's Based on Standardized Items giving the value 0.631 and 0.542 . For all questions in this section, the value of the mean is $35.20,10.200$ for a variance and the last one is standard deviation which is 3.194

\subsection{Introduction of Project Management}

Section A of the survey is related to introduction to project management. This section will be asked to achieve the last objectives, which is to measure the degree of awareness and implementation of project management in SMEs manufacturing companies. This introductory section is focused on awareness of project managements in small and 
medium manufacturing companies. The questions start with multiple-choice questions that asked the respondents either they have heard about project management and had implemented in their company or not.

Then, the following questions on a project management statement have a relation to the question before. The idea of this statement is about basic understanding and meaning of a project management. If the respondents have a basic knowledge and understanding of project management, they can answer the questions correctly.

It is found that $80 \%$ of the respondents get the concept of project management clearly and the remaining need to improve to clear the confusion of project management. The majority has heard of project management and $80 \%$ on the next questions choose that project management is "very important" to their company performance.

Table 4: Reliability Test on Implementation of Project Management (Section A)

\begin{tabular}{|c|c|c|c|c|c|c|c|}
\hline \multicolumn{8}{|c|}{ Reliability Statistics } \\
\hline Cronbach's & & Cronbach' & Alpha Based o & Standarc & d Items & No. of Items & \\
\hline \multicolumn{2}{|c|}{.800} & \multicolumn{4}{|c|}{.800} & \multicolumn{2}{|l|}{4} \\
\hline \multicolumn{8}{|c|}{ Summary Item Statistics } \\
\hline & Mean & Minimum & Maximum & Range & $\begin{array}{c}\text { Maximum / } \\
\text { Minimum }\end{array}$ & Variance & $\begin{array}{l}\mathrm{N} \text { of } \\
\text { ltems }\end{array}$ \\
\hline Item Means & 1.500 & 1.200 & 1.800 & .600 & 1.500 & .120 & 4 \\
\hline
\end{tabular}

Scale Statistics

\begin{tabular}{cccc}
\hline Mean & Variance & Std. Deviation & N of Items \\
\hline 6.00 & .500 & .707 & 4 \\
\hline
\end{tabular}

Table 5: Reliability Test on Implementation of Project Management (Section B)

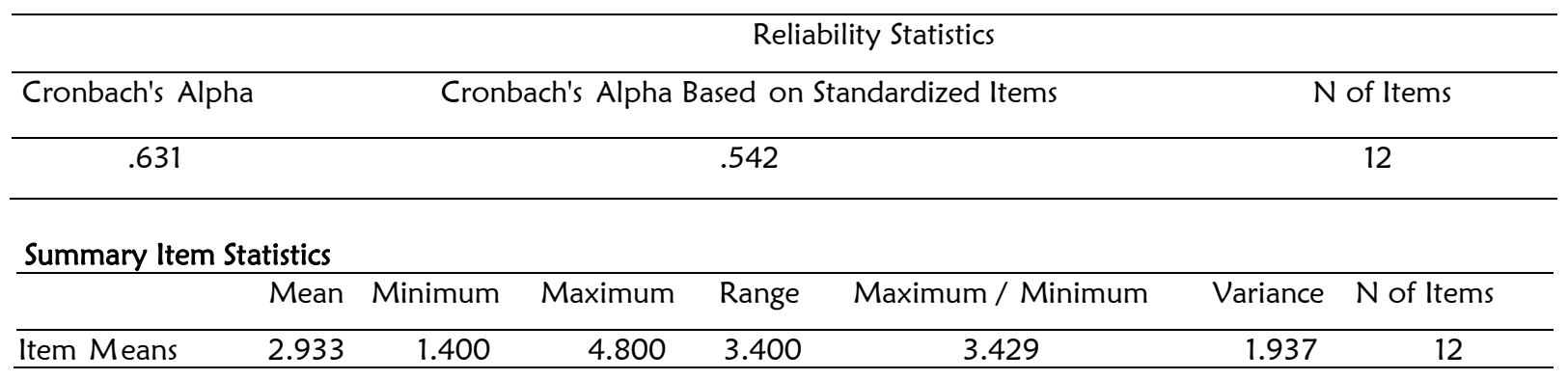

\section{Scale Statistics}

\begin{tabular}{cccc}
\hline Mean & Variance & Std. Deviation & N of Items \\
\hline 35.2 & 10.2 & 3.194 & 12 \\
\hline
\end{tabular}

\subsection{Implementation of Project Management}

Time estimation to complete project leads the overall question in section B that is in the implementation of project management section. 'Iron Triangle' also includes in the life cycle elements of project management, which is planning, monitoring and control. It includes all aspects of a project to achieve the project objectives on time, within cost estimated and meet the quality and performance [7].

Based on the results of time estimation question in the implementation of project management section, no respondents choose the answer not more than 12 months to complete a project from start to finish. This is a positive result, since they did not have to spend too much time on particular projects. Therefore, the projects will achieve objectives that includes in 'Iron Triangle' that is completing a project on specific time. Subsequently, respondents required to choose more than one answer on multiple-choice questions regarding project management tools. In a project, there are a large number of activities required in order to complete a project successfully. Thus, to ensure 
they are complete on schedule and to make sure that the project do not miss a deadline, project management tools is very helpful to be able to see everything that needs to be done. Respondents will be able to choose this project management tool correctly if they are aware of project management. The type of questions that has specific answer will be able to measure the degree of awareness in project management. Based on our data collected, $60 \%$ respondents answer this question correctly. It can be assumed that the respondents cannot differentiate clearly on project life cycle methodology and project management tools. They have some knowledge on project management, but it is not enough on particular aspects.

Schedule and performance as the project's goals in five-scale question type, whether the following goals met the plan or not. The five scale points questions are divided into $1=$ never met, $2=$ seldom met, $3=$ sometimes met, $4=$ often met and $5=$ always met. In addition, based on section $A, 100 \%$ respondent's response that they implemented project management in their project. Therefore, this five-scale question will be able to show us their effect on budget, schedule and performance when they apply project management. This can be one of the positive proofs when they apply project management in their project. Based on the data collected, the least scale that chooses by the respondents is sometimes met which is scale 3. It is a good sign but its still cannot do $100 \%$ on scale 5 with budget, schedule and performance goals. From that response, they know and heard about project management but only apply a little bit of it.

The following questions on the survey are still using five-scale question method. To be clear about the scale for the last part of the survey below, they are divided into $1=$ not important, $2=$ slightly important, $3=$ important, 4 = fairly important and 5 = very important. There are 3 models of success factor criteria discussed in the literature review. There are Pinto's model of ten critical success factors, Kerzner's critical success factor and also Belassi and Tukel's critical success factor. The implementation of project management will be shown from the results of four success criteria chosen generally. The first success criteria are top management support. In Pinto's model, top management support listed as one of the critical success factors in project management. Kerzner's model is using executive commitment and leadership approach that will be assumed as top management support from the executive and leadership words. The last one will be Belassi and Tukel's model that divided the factors related to the project manager and the team members as well as organization. Every single detail discussed in three models, explained about top management support. It is a strong point on critical success factor that will be a huge impact on the implementation of project management. Based on the response in figure 5.5 , it can be concluded that scale 4 and 5 only that had been chosen by the respondents. To get the support from top management support, project initiation must be applied. Therefore, it is one of the proof that the respondent had implemented project management.

To measure the degree of implementation of project management, success criteria can be part of the successful implementation of project management. Clear goals and objective is chosen as one of the success criteria. According to figure 5.6, 80\% choose clear goals and objectives as important to their projects and organization and the rest $20 \%$ choose very important in their response. Project mission in Pinto's model, clear understanding of project management in Kerzner's model and factors related to the project from Belassi and Tukel's model is included in clear goals and objective success criteria. To get clearer goals and objectives, they need to plan. Planning is one of the aspect in the project management life cycle and it shows that they had implemented project management based on project planning.

Most of the respondents ( $80 \%$ ) choose that it is very important for planning and control to their projects and organization. Pinto's model stated that project proposal and schedule as their critical success factor in their model. Kerzner's critical success factor stated the sixth points, which are commitment to planning and control and also Belassi and Tukel's include factors related to the project and both for sure can be listed as critical success factors. Again, project initiation and planning in project management life cycle involved in planning and control. The results indirectly show that all the respondents implemented project management when they choose fairly and very important planning and control of their projects and organization.

More than half respondents, which are $60 \%$, choose that it is very important to have an excellent project manager as success criteria for their projects and organization. Personnel elements, monitoring and feedback element, communication element as well as trouble shooting element in Pinto's model need excellence project manager. On Kerzner's critical success factor, there is a strong point on excellent project manager. Finally yet importantly, in Belassi and Tukel's model, factors related to the project manager and team members are involved. Thus, it can be assumed that excellence project manager leads to the positive results on the elements listed. Based on the initiation phase in the project management life cycle, project manager and team are appointed. At this phase, it is very important to choose the most excellence project managers in order to make sure everything will be in control. As a conclusion, project initiation is involved and it shows that the respondents had applied the project management to their projects and organization.

\section{CONCLUSIONS AND RECOMMENDATIONS}

\subsection{Conclusions}

The objectives of this project have been successfully achieved through the study of the project management approach for typical small to medium manufacturing companies in Pahang and Sarawak. These two states are selected because there is the largest state in peninsular and east Malaysia. To start with the objectives of this 
report, this study helps to identify problem areas in applying project management in SMEs that focusing on manufacturing companies. The problem areas were discussed in general first before the scope of the topic is narrowing to be focused on small and medium manufacturing companies. When there is a problem, there is a way. Therefore, to eliminate all the problems, this study also recommends solutions and ways forward against identified problem areas. Finally yet importantly, the survey used in this study was to measure the degree of awareness and implementation of project management in small to medium manufacturing companies. In the survey, success criteria based on three success factor models in project management and SMEs operations were selected to design a question in section B. Four success criteria are selected from success factor model listed in this literature review chapter. There are Pinto's, Kerzner's and also Belassi and Tukel's critical success factors. These four criteria in three-success factor model are selected because they give a huge impact on project management. Using a survey conducted, data are collected and discussed. From our study, the level of awareness and implementation of project management especially is small and medium-manufacturing companies are quite satisfactory. Most of the manufacturing companies are implementing project management, but the level is depending on the organization in the company itself. Most of the problem and the solutions listed were from the organization itself. From top management to the workers itself, a project management concept must be fully understood by all levels in order to help the companies to gain the confidence that the project management can help the companies a lot to move forward.

\subsection{Recommendations}

It is strongly recommended that this project is taken for further analysis to increase the number of respondents as a number of manufacturers is increasing by the year. In facts, the respondents for this study have represented manufacturing companies with small to medium manufacturing companies because they are chosen from SME Corporation Malaysia website directory. SME Corporation Malaysia is the most reliable agency because it is a central coordinating agency under the Ministry of International Trade and Industry Malaysia Furthermore; the respondents are from Pahang and Sarawak. This is because Pahang is the largest state in peninsular Malaysia and Sarawak is the largest state in east Malaysia.

A further collection of data is needed not only the companies registered under SME Corporation Malaysia to increase the reliability of the findings. Technique of conducting the survey must be improved since the response rates are low. Apart from that, supporting letter from SME Corporation Malaysia also can be used as a platform to submit a survey questionnaire and develop communication with the respondent for further study. Since the understanding of project management in small to medium manufacturing companies is considered quite satisfactory, introducing the new guidelines to apply the full concept of project management is necessary to develop interest and motivation for the companies to be applied in all areas within the organization.

\section{ACKNOWLEDGEMENT}

The authors would like express their sincere gratitude to all respondents for their time and effort. The authors also would like to appreciate very much the support from Department of Manufacturing and Materials Engineering to facilitate data collection and proving the analytical support.

\section{REFERENCES}

1. SME Annual Report 2014 /2015, Retrieved from www.smecorp.gov.my/index.php/en/resources/2015-1221-11-07-06/sme-annual- report-2014/2-annual-report. 157.

2. SME Annual Report 2015 /2016, Retrieved from www.smecorp.gov.my/index.php/en/resources/2015-1221-11-07-06/sme-annual- report/book/69-annual-report-2015-16/2-annual-report. 186.

3. Economic Census (2011) - Profile of Small \& Medium Enterprise. Retrieved from https://www.statistics.gov.my/dosm/uploads/files/BanciBE/Penerbitan_Profil_PKS_20 11.pdf.

4. Morris, P. W. G. (2011). A brief history of project management.

5. Turner, R., Ledwith, A., \& Kelly, J. (2010). Project management in small to medium-sized enterprises: Matching processes to the nature of the firm. International Journal of Project Management, 28(8), 744-755.

6. Bahnaier, W. W. (2001). Scheduling Guide for Program Managers. DIANE Publishing. Barron, M., \& Barron, A. (2009). History of Project Management. Connexions, September,

7. Atkinson, R. (1999). Project management: cost, time and quality, two best guesses and a phenomenon, its time to accept other success criteria. International Journal of Project Management, 17(6), 337 - 342.

8. Kerzner H. (1998). In Search of Excellence in Project Management. John Wiley and Sons.

9. Ihesiene, U. C. (2014). A Survey-based Study of Project Management Problems in Small and Medium Scale Enterprises (SMEs) in Nigeria. European Scientific Journal, 10(25).

10. Sarah Marley (2014). The Importance and Effect of Sample Size. Retrieved October 28, 2016, from https://select-statistics.co.uk/blog/importance-effect-sample-size/ 